\title{
A Study of Hormonal Effects in Cervical Smear Samples Using Raman Spectroscopy
}

D. Traynor

Technological University Dublin

P. Kearney

Technological University Dublin

I. Ramos

Technological University Dublin

See next page for additional authors

Follow this and additional works at: https://arrow.tudublin.ie/radart

Part of the Chemicals and Drugs Commons

\section{Recommended Citation}

Traynor, D., Kearney, P., Ramos, I., Martin, C.M., O'Leary, J.J. \& Lyng, F. (2018). A study of hormonal effects in cervical smear samples using Raman spectroscopy. Journal of Biophotonics, 11(6), e201700240. doi:0.1002/jbio. 201700240

This Article is brought to you for free and open access by the Radiation and Environmental Science Centre at ARROW@TU Dublin. It has been accepted for inclusion in Articles by an authorized administrator of ARROW@TU Dublin. For more information, please contact arrow.admin@tudublin.ie, aisling.coyne@tudublin.ie, gerard.connolly@tudublin.ie.

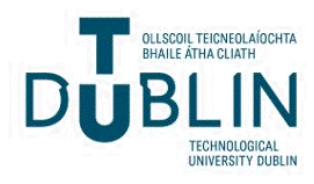




\section{Authors}

D. Traynor, P. Kearney, I. Ramos, C. M. Martin, J. J. O'Leary, and Fiona Lyng

This article is available at ARROW@TU Dublin: https://arrow.tudublin.ie/radart/68 


\section{Introduction:}

There were an estimated 527,600 new cervical cancer cases and 265,700 deaths from cervical cancer worldwide in 2012 (Torre et al., 2015). Until recently the primary method for cervical screening was based on the Papanicolaou test (Pap test). The Pap test requires cells to be scraped from the cervix, fixed to a glass slide, stained and reviewed by a trained cytologist. Cellular abnormalities are identified by the cytologist based on cellular morphology and staining characteristics and classified according to the degree of dysplasia (Low grade or High grade). The advantage of the Pap test is that it is a non-invasive and widely accepted screening based test with a high specificity of $95-98 \%$ and a sensitivity of $74-96 \%$ ( Kitchener et al., 2011). The variability in the rates of sensitivity can be due to sampling technique; the subjectivity of the cytology based screening and can result in a high rate of gynaecological referral and patient recall which adds to cost and patient stress. Persistent infection with high risk human papillomavirus (HPV), such as HPV types 16, 18, is accepted as the major cause of cervical pre-cancer and cancer (Walboomers et al., 1999)(Ronco et al., 2010). HPV DNA testing has a higher sensitivity (>95\%) but lower specificity ( 84\%) than the Pap test (Cuzick et al., 2013) and these tests are expensive, time-consuming and provide no information on cervical cytopathology. Current gold standard methods for detection of cervical cancer and precancer are therefore limited and there is an unmet clinical need for new objective screening or diagnostic tests. Optical spectroscopic techniques, such as Raman or infrared spectroscopy, are label-free, non-invasive and have several advantages over traditional approaches, including objectivity, speed and cost. These methods can provide quantitative information based on the spectroscopic signature of the biochemical components of the sample allowing diagnosis to be based on biochemical changes rather than on morphological changes. The focus of the present study is on Raman spectroscopy which is based on inelastic light scattering. The coupling of the light generates vibrations within the material and these vibrations are characteristic of the 
chemical structure, the energy of the scattered light is reduced by an amount equal to the vibrational energy and from this a rapid, label free, non-destructive measurement of the complete biochemical fingerprint of a biological sample can be obtained. Over the past 15 years, the potential of Raman spectroscopy together with multivariate statistical analysis has been demonstrated for the detection of a variety of cancers, including cervical cancer (Diem et al., 2013) (Lyng et al., 2015) In initial infrared spectroscopy studies on cervical cytopathology samples (González-Solís et al., 2014)(González-Solís et al., 2013)(Wong et al., 1991), spectra were recorded from cell pellets rather than from single cells and the presence of metaplastic cells, endocervical columnar cells, polymorphs, blood, cervical mucus and debris were all identified as confounding factors (Wong et al, 2002)(Chiriboga et al., 1998)(Cohenford et al., 1997)(Diem et al., 2002) (Romeo et al., 2003) (Wood et al., 1998). Recent studies by (Ramos et al., 2016) and (Bonnier et al., 2014) addressed the variability in Raman spectra from cervical smear samples and reported a new method to clear blood residue contamination before Raman spectroscopy based on pre-treatment of the slides with hydrogen peroxide. This method significantly minimised variability and resulted in the collection of highly reproducible data and was employed in this study to reduce variability based on the presence of blood residue. Physiological factors such as hormonal changes during the menstrual cycle or during menopause may also be potential sources of variability in the normal cervix.

The cellular make up of an individual woman's smear is dependent on which day during the menstrual cycle the sample was taken. Days 1-4 are classed as the menstruation phase of the cycle when bleeding will occur and smear samples are generally not taken during this phase. Days 5-13 are classified as the proliferative phase. During this phase oestrogen levels reach their peak resulting in complete maturation of the squamous epithelium and the cervical smear will present with a higher ratio of superficial cells to intermediate cells. Days 14-28 are 
classified as the secretory phase where progesterone production reaches its peak and prevents complete maturation of the epithelium. The cervical smear will present with a higher ratio of intermediate cells to superficial cells. During menopause, levels of both oestrogen and progesterone will drop dramatically and there is a gradual arrest of the maturation of the squamous epithelium. This results in the loss of superficial and intermediate cells leading to the final atrophic stage where the squamous epithelium is composed entirely of parabasal cells.

The use of hormone based contraceptives (HC) will affect the natural hormone mediated maturation process of the cervical epithelium. A study by (Romeo et al., 1998) used infrared spectroscopy to investigate hormonal influences on cervical cells throughout the menstrual cycle and showed spectral changes such as increases in the $1200-1000 \mathrm{~cm}^{-1}$ region due to glycogen increases around ovulation (mid cycle). Cervical cells from women on HC did not show the same degree of spectral changes as cells from women not on HC. Despite the variability throughout the menstrual cycle, principal component analysis (PCA) showed good discrimination between high grade dysplasia and normal samples collected at different phases of the menstrual cycle.

A more recent study by (Kanter et al.,2009) has shown that hormonal differences due to the menstrual cycle can influence the Raman spectra acquired from the cervix in vivo. Spectra were divided into four groups, pre-menopausal proliferative phase (days 1-14), premenopausal secretory phase (day 15-28+), peri-menopausal and post-menopausal. Spectral differences were mainly observed at 1250, 1300 and $1320 \mathrm{~cm}^{-1}$, most likely due to changes in the proteins collagen and elastin (Movasaghi et al.,2007). Incorporating hormonal status into their dysplasia classification algorithm increased the classification accuracy from 88\% to 94\%.

The main objective of our study was to investigate hormone associated changes in the Raman spectra of cytologically negative ThinPrep cervical smear samples related to; (1) the menstrual cycle, (2) the onset of menopause and (3) the use of hormone based contraceptives. 
A further objective was to determine if any changes observed would interfere with the ability to discriminate normal and high grade dyskaryotic cervical smear samples caused by HPV infection.

\subsection{Materials and methods}

\subsubsection{Sample collection and ThinPrep slide preparation}

Cervical smear samples collected in PreservCyt solution were obtained from the Cytology Department at the Coombe Women and Infants University Hospital (CWIUH), Dublin, Ireland, after routine cytological screening had been performed. Ethical approval for use of anonymised samples for the study was granted by the CWIUH Research Ethics Committee (no. 28-2014). Clinical data which was recorded relating to the samples included cytology result, date of last menstrual period, age at time of smear test and reported use of hormonal based contraceptives. No information on smoking status was available. A total of 60 cervical smear samples, 45 confirmed as cytology negative and 15 confirmed high grade dyskaryosis (high grade squamous intraepithelial lesion (SIL)) samples, were used for this study.

A slide was prepared for each sample using a ThinPrep 2000 processor (Hologic Inc; Marlborough, MA 01752). The Thin Prep processor starts by homogenizing the sample by spinning the filter, creating shear forces in the fluid that are strong enough to disaggregate randomly joined material, break up blood, mucus and non-diagnostic debris. The cells are then collected onto the membrane of the filter and transferred onto a glass slide to create a circular monolayer deposit of cells $20 \mathrm{~mm}$ in diameter and a few microns in thickness. The slide is then ejected automatically into a fixative bath of $95 \%$ ethanol.

The presence of blood residues on ThinPrep slides is a limiting factor that needs to be removed in order to collect data with minimal variability. Therefore the slides were treated 
with a $30 \%$ solution of $\mathrm{H}_{2} \mathrm{O}_{2}$ at room temperature for 3 minutes. The slides were then placed into a 70\% solution of industrial methylated spirits (IMS) for 3 minutes followed by multiple dips into $100 \%$ IMS to remove any remaining cellular debris and $\mathrm{H}_{2} \mathrm{O}_{2}$. The slide was then air dried.

\subsubsection{HPV Testing}

$1 \mathrm{ml}$ of the remaining test sample was tested for HPV using the Cobas 4800 HPV test. The Cobas 4800 test is an automated extraction and real time PCR system that is capable of identifying 14 different high risk HPV types as well as the ability to genotype for HPV 16/18. The Cobas 4800 test starts by first collecting $400 \mu$ of the test sample and heating it up to start the denaturing process. The cells are then lysed by a chaotropic reagent. The lysis step releases the HPV nucleic acids. These nucleic acids are negatively charged which bind to positively charged magnetic glass particles, which are held in place by a magnetic plate. The nucleic acids are then washed and separated from the glass particles, before they are amplified and detected by RT-PCR. Sequences of approximately 200 nucleotides are targeted by primers for the PCR reaction. The nucleotides are located within the L1 region of the HPV genome, with the master mix containing the primers designed for 14 different high risk HPV genotypes $(16,18,31,33.35,39,45,51,52,56,58,59,66$ and 68). Fluorescent oligonucleotides are then added which can bind to the sequences within these primers during the PCR. The detection of these fluorescent oligonucleotides will give either a positive or negative result. 


\subsubsection{Raman Microspectroscopy}

Raman studies were performed using a Horiba Jobin Yvon XploRA system (Villeneuve d’Ascq, France) which incorporates the Olympus microscope Bx41. As source, a 532 nm laser of $\sim 12 \mathrm{~mW}$ power was focused onto the sample using a 100X objective (MPlan, Olympus, NA $=0.9$ ) giving a spot size of $1-2 \mu \mathrm{m}$. The confocal hole was set at $100 \mu \mathrm{m}$ for all measurements, the specified settings for confocal operation. The system was pre-calibrated to the $520.7 \mathrm{~cm}^{-1}$ spectral line for silicon. The 1200 lines per mm grating was used. The backscattered light was measured using an air cooled CCD detector (Andor, 1024-256 pixels). The spectrometer was controlled by Labspec V5.0 software. For each cell, one spectrum was recorded from the nucleus for 2 accumulations of 30 seconds in the spectral range of $400-1800 \mathrm{~cm}^{-1}$. Spectra were recorded only from the cell nucleus as these have been found to be more reproducible and consistent than spectra from the cell cytoplasm. On average 30 cells were recorded from each sample (superficial and intermediate cells). The $\mathrm{x}, \mathrm{y}$ co-ordinates of each cell was recorded on the Raman microscope. After Raman acquisition was complete and following Pap staining, each cell could be re-visited and assigned as superficial or intermediate. The 15 high grade dyskaryotic smears were screened for HSIL cells and spectra recorded accordingly. 


\subsubsection{Data Pre-Processing and Analysis}

Data was normalised and analysed using Matlab software (Mathworks) and specific scripts developed and adapted for uploading of the spectra and their pre-processing, including smoothing (Savitzky-Golay $\mathrm{K}=5, \mathrm{~K}=13$ ), baseline correction (Rubberband) and vector normalization. An in house method for glass removal based on non-negativity constrained least squares was used to remove the spectral features of glass (Kearney et al., 2017). The algorithm weights the values of glass as well as cell components in the acquired spectra from the cell and further subtracts the glass from the cell spectra applying non-negative constraints. Classification methods find mathematical models that are able to recognize the membership of each sample to its appropriate class on the basis of a set of measurements. When the classification model has been calibrated, the membership of unknown samples to one of the defined classes can be predicted. Although PCA-LDA is the standard method used to maximise the variations in the $\mathrm{X}$ direction, PLS-DA by rotating both the $\mathrm{X}$ and $\mathrm{Y}$ axes allows even small variations to be captured. This was necessary to identify the normal biochemical changes associated with the menstrual cycle. Partial Least Squares Discriminant Analysis (PLS-DA) was used to build classification models in this study together with leave-one patient-out crossvalidation. PLS-DA analysis was performed using the PLS toolbox (Eigenvector Research) in the Matlab (Mathworks Inc.) environment.

From the data provided by the patient about their last menstrual period and the day on which the sample was taken, the day of the menstrual cycle the smear was taken was calculated. It was assumed that each patient follows the standard 28 day cycle. Samples were only available from days 7-24 of the cycle. Table 2 shows the sample details including day of the menstrual cycle, menopausal status and use of hormone based contraceptive (HC). 


\begin{tabular}{|c|c|c|c|c|c|}
\hline Sample number & $\begin{array}{l}\text { Cytology } \\
\text { Result }\end{array}$ & Day of cycle & Postmenopausal & HPV Result & Contraceptive \\
\hline 1 & Negative & 7 & l & Negative & None \\
\hline 2 & Negative & 9 & / & Negative & None \\
\hline $3,4,5,6,7$ & Negative & 10 & l & Negative & None \\
\hline 8,9 & Negative & 11 & l & Negative & None \\
\hline $10,11,12,13,14$ & Negative & 12 & / & Negative & None \\
\hline $15,16,17,18,19,20,21,22$ & Negative & 13 & l & Negative & None \\
\hline 23,24 & Negative & 16 & I & Negative & None \\
\hline 25,26 & Negative & 20 & / & Negative & None \\
\hline 27 & Negative & 21 & / & Negative & None \\
\hline 28 & Negative & 24 & I & Negative & None \\
\hline 29, 30, 31, 32, 33, 34, 35 & Negative & / & Postmenopausal & Negative & l \\
\hline $\begin{array}{l}36,37,38,39,40,41,42,43 \\
44,45\end{array}$ & Negative & l & / & Negative & $\begin{array}{l}\text { Hormone based } \\
\text { Contraceptive }\end{array}$ \\
\hline $\begin{array}{l}46,47,48,49,50,51,52,53 \\
54,55,56,57,58,59,60\end{array}$ & High Grade & l & / & Positive & None \\
\hline
\end{tabular}

Table 3.1 Sample details including day of the menstrual cycle, menopausal status and use of hormone based contraceptive 


\subsection{Results and Discussion}

\subsubsection{Proliferative and Secretory Phase and Postmenopausal Cellular Presentation on Pap smear.}

The proliferative and secretory phase presentation of a Pap smear are shown in Figure 3.1(A) and Figure 3.1(B) respectively. A higher ratio of superficial (pink stained) to intermediate (blue stained) cells in the proliferative phase compared to a higher ratio of intermediate (blue stained) to superficial (pink stained) cells in secretory phase can be observed. A postmenopausal Pap smear is shown in Figure 3.1(C). A lack of cellular material, mucus and cellular debris can be observed which caused difficulties in recording good quality spectra.
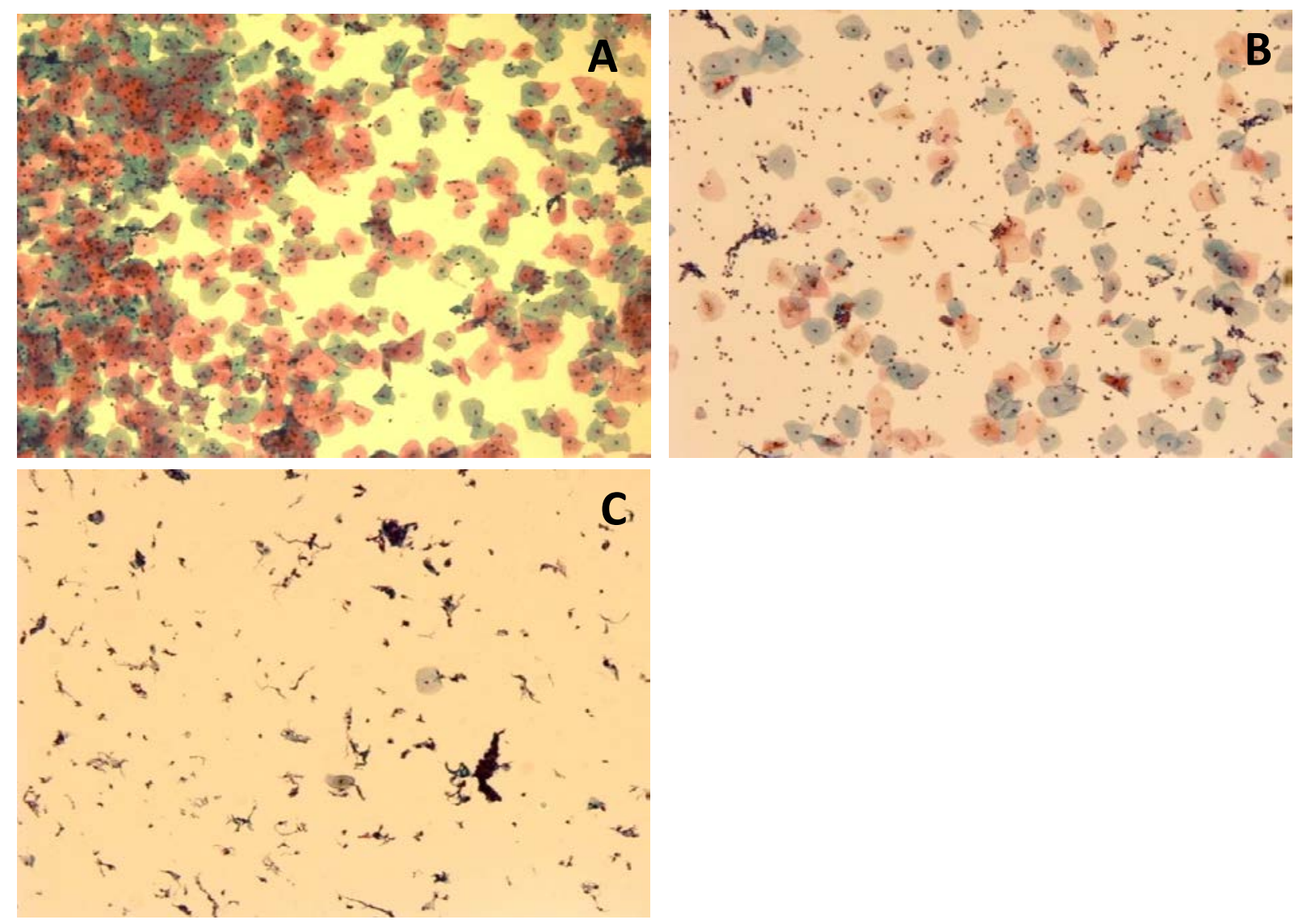

Figure 3.1 (A) Proliferative phase presentation of a Pap smear. Note the higher ratio of superficial (pink stained) to intermediate (blue stained) cells, (B) Secretory phase presentation of a Pap smear. Note the higher ratio of intermediate (blue stained) to superficial (pink stained) cells, (C) Postmenopausal presentation of a Pap smear. Note the lack of cellular material, mucus and cellular debris. Bar $=35 \mu \mathrm{m}$. 


\subsubsection{Raman signature of Proliferative Phase Vs Secretory Phase}

The spectral data from the Pap smears was divided up according to the day of the menstrual cycle the sample was taken on. Figure 3.2(A) shows the mean Raman spectra of cells from days 7 to 24 of the menstrual cycle. Increases in the Amide I $\left(1640-1650 \mathrm{~cm}^{-1}\right)($ see Table 1$)$, Phenylalanine and Tyrosine (1605-1610 $\left.\mathrm{cm}^{-1}\right)$ and glycogen $\left(480 \mathrm{~cm}^{-1}\right)$ bands over time were observed. The latent variables (LV) scores scatter plot Figure 3.2(B) shows reasonable separation between the proliferative phase (blue) and the secretory phase (red). Some overlapping is observed which is most likely due to the fact that each woman will differ slightly between the days of the menstrual cycle and the levels of oestrogen and progesterone present. The LV1 loadings shown in Figure 3.2(C) highlight areas similar to those highlighted in the mean Raman spectra Figure 3.2(A). The discrimination is mainly based on glycogen (480, 937, 1381, $1458 \mathrm{~cm}^{-1}$ ) which is more present in the secretory samples (red) due to the higher levels of progesterone which promotes sub nuclear glycogen accumulation (Nair et al., 2010) and proteins $\left(\mathrm{CH}_{2}\right.$ def, $\left.1450 \mathrm{~cm}^{-1}\right)$ and Amide I $\left(1669 \mathrm{~cm}^{-1}\right)$ which are higher in samples collected from the proliferative phase of the cycle. The prediction plot from the PLS-DA model Figure 3.2(D) shows reasonably good classification of menstrual cycle phase (proliferative phase or secretory phase) with sensitivity of $83 \%$ and specificity of $86 \%$.

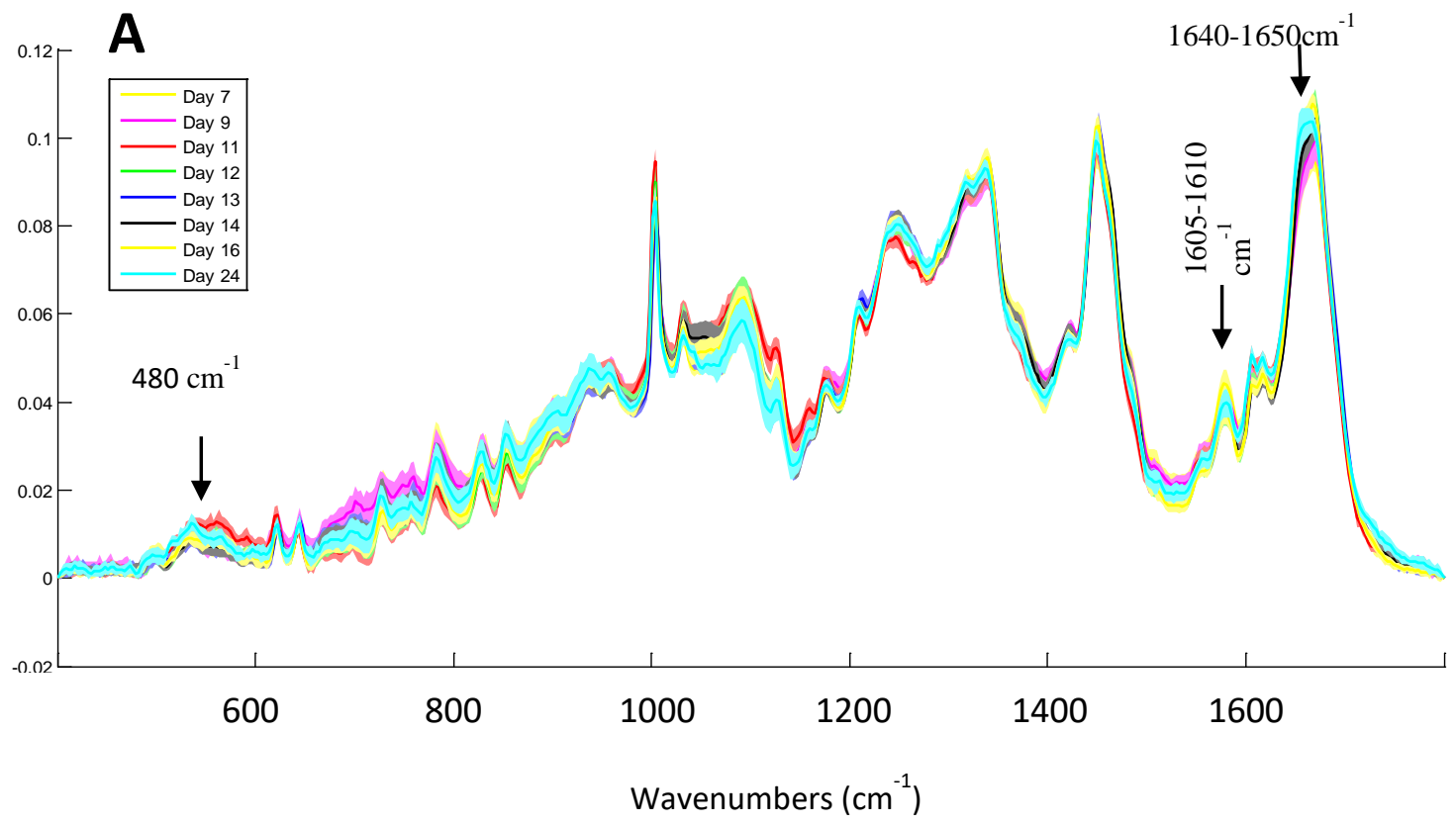



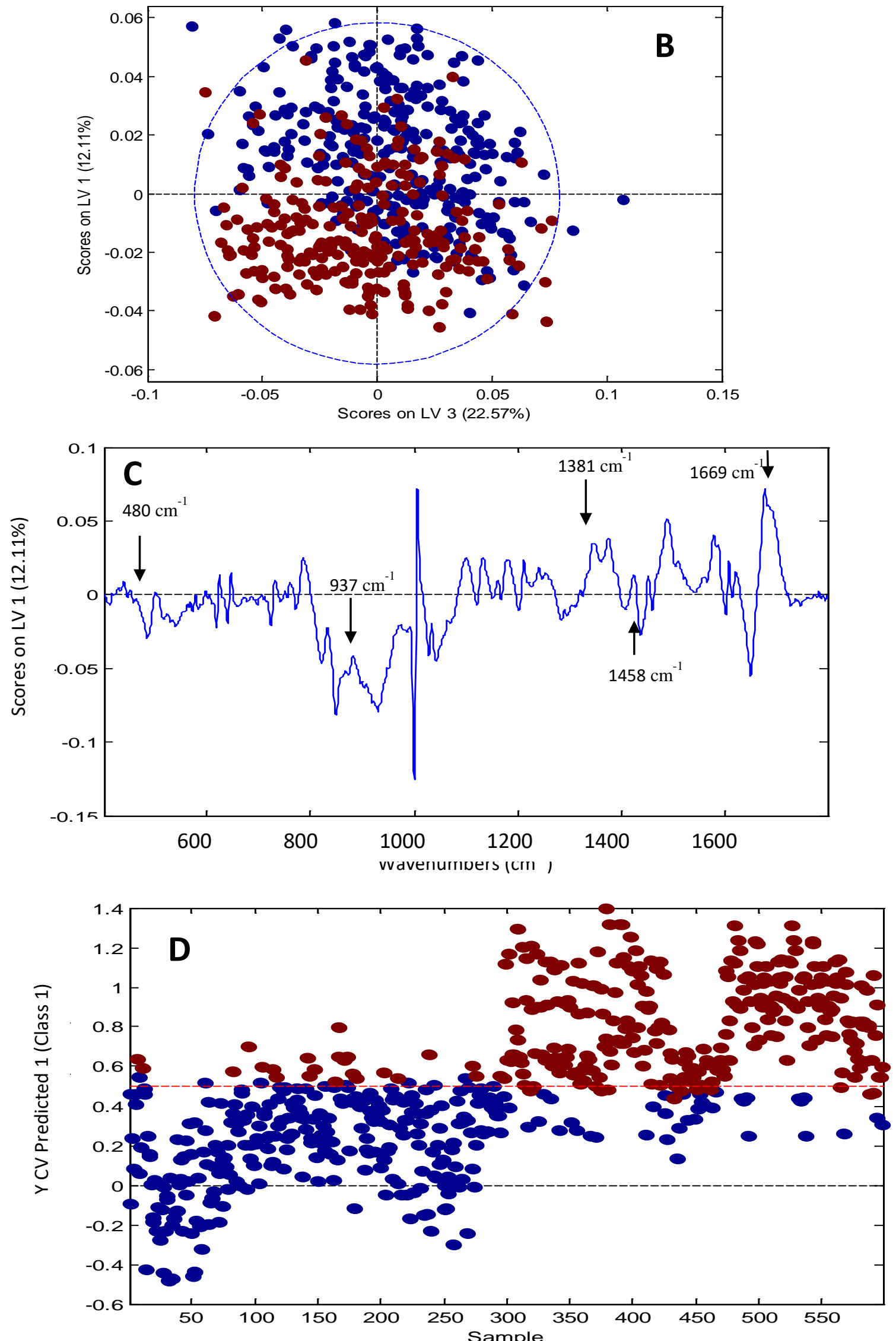

Figure 3.2 (A) Mean Raman spectra of intermediate and superficial cells from days 7 to 24 . Shading denotes the standard deviation, (B) LV scores scatter plot of Proliferative Phase, Days 7-14 (Blue) Vs Secretory Phase, Days 15-24 (Red ), (C) LV1 loadings, (D) PLS-DA prediction plot. 


\subsubsection{Raman signature of postmenopausal samples}

Most women are generally screened for cervical cancer up until the age of 65. Between the ages of 48-55 most women are said to be menopausal. Hence it is important to determine if Pap smears collected from postmenopausal women will have a similar Raman signature to nonpostmenopausal women. Mucus and cellular debris present on postmenopausal samples obscure the little cellular material that is present on the slide and make it very difficult to obtain good spectra hence the number of spectra recorded is severely reduced and it is difficult to draw any firm conclusions. Figure 3.3(A) shows the mean and standard deviation spectra of the 22 postmenopausal cells recorded. Figure 3.3(B) shows good discrimination between the two sample types. The loadings shown in Figure 3.3(C) shows that the discrimination is based on glycogen (852, 1106, $\left.1138 \mathrm{~cm}^{-1}\right)$ and nucleic acids $\left(781 \mathrm{~cm}^{-1}\right)$ proteins $\left(1450 \mathrm{~cm}^{-1}\right)$ and Amide I (1669 $\left.\mathrm{cm}^{-1}\right)$. Figure 3.3(D) shows the PLS-DA prediction plot which has a sensitivity of $100 \%$ and specificity of $95 \%$.

Atrophic samples were not available as part of this study. No firm conclusions can be drawn from this data set except that postmenopausal samples can represent a problem for Raman based screening based on their Pap smear presentation due to mucus, cellular debris and lack

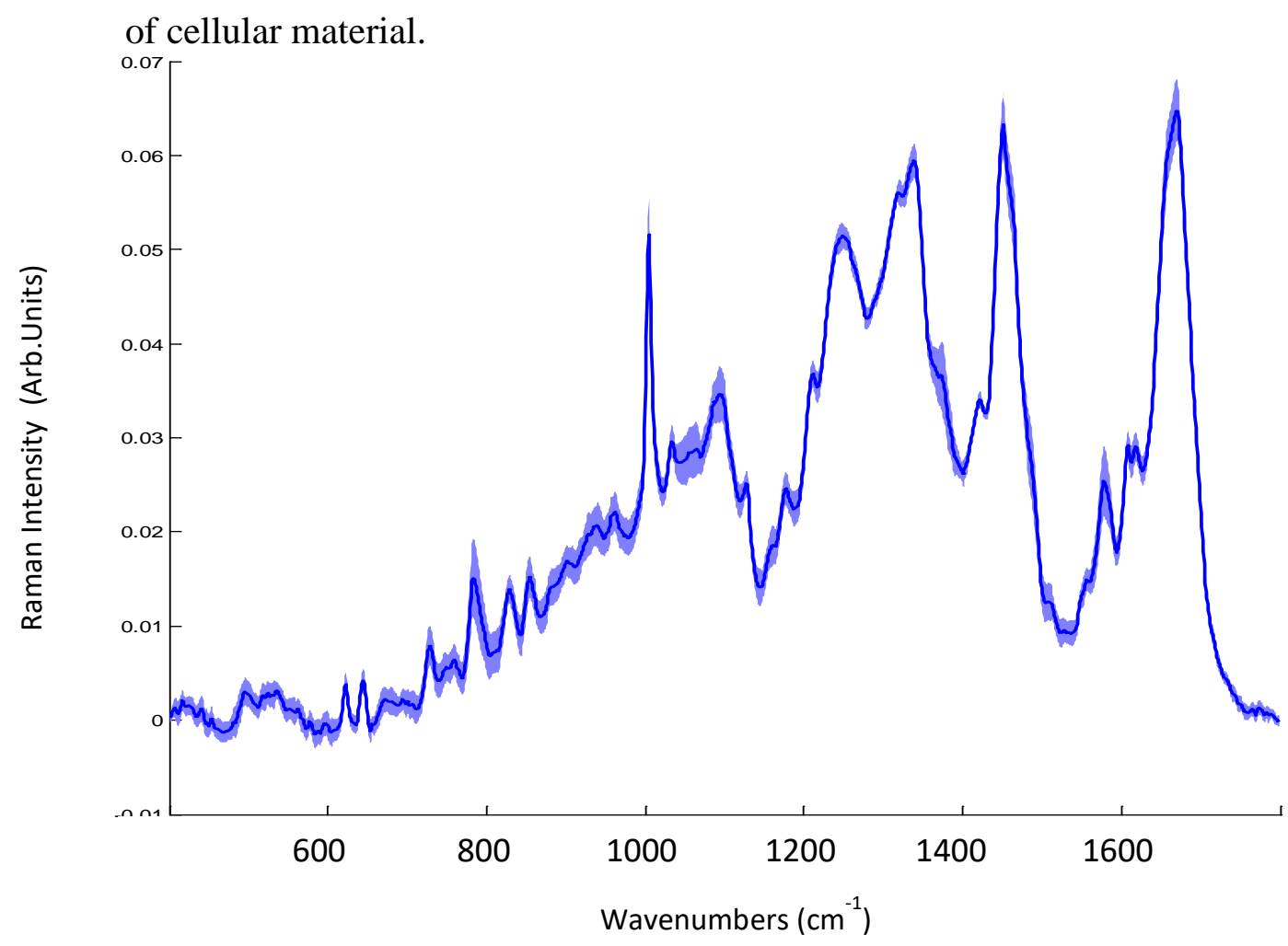



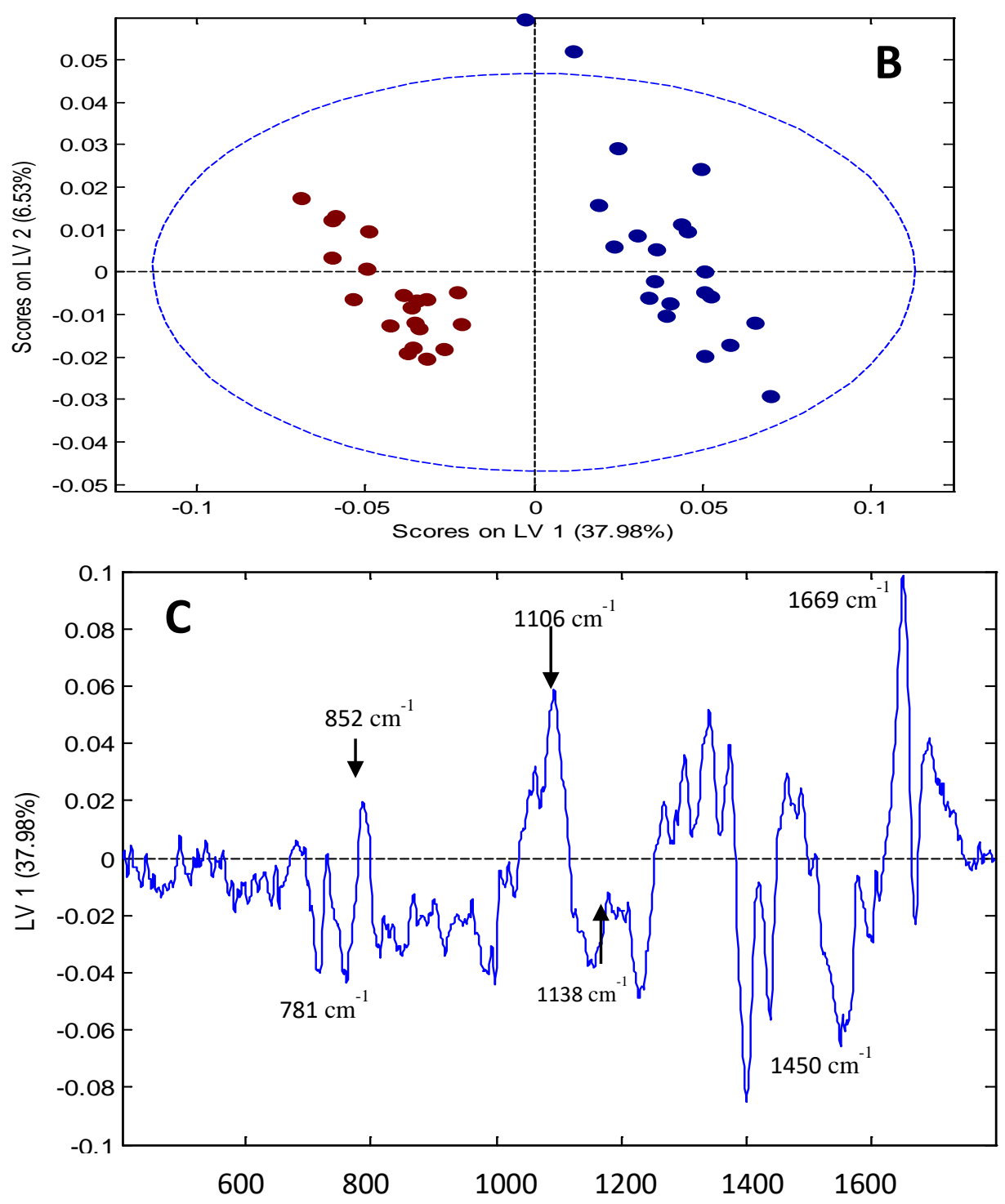

Wavenumbers $\left(\mathrm{cm}^{-1}\right)$

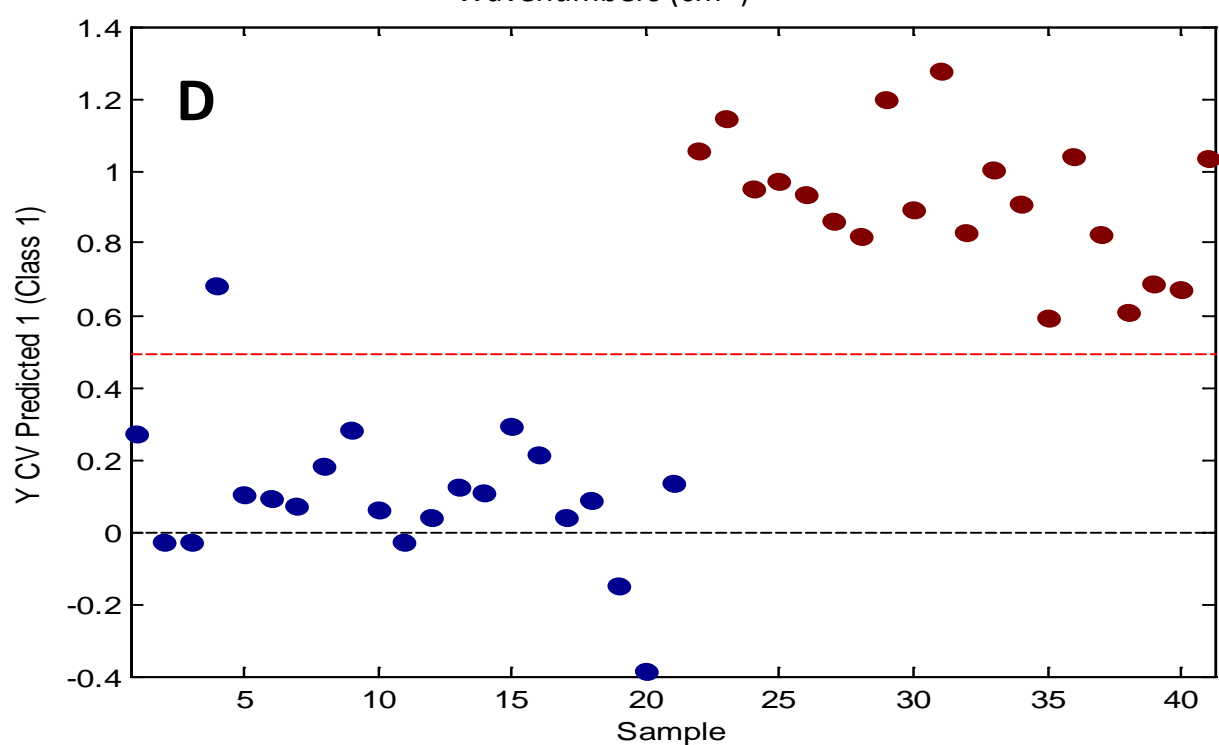

Figure 3.3 (A) Mean Raman spectra from postmenopausal samples. Shading denotes the standard deviation, (B) LV scatter scores plot of postmenopausal (blue) and non-menopausal (red), (C) LV1 loadings, (D) PLS-DA prediction plot 


\subsubsection{Raman signature associated with women on hormone based contraceptives.}

The clinical details obtained indicated if the patient was on some form of hormone based contraceptive (HC). However information on which type of contraceptive they are currently on was not included. The aim of this part of the study was to determine if Pap smears collected from women on HC will have a similar Raman signature to women who are not on HC. Figure 3.4(A) shows that the levels of glycogen $\left(482 \mathrm{~cm}^{-1}\right.$ and $\left.855-939 \mathrm{~cm}^{-1}\right)$ in the HC positive samples are lower when compared to the controls. The controls were made up of the samples collected throughout the menstrual cycle which were HC negative. Tryptophan and Phenylalanine at peak position (1584-1605 $\left.\mathrm{cm}^{-1}\right)$ and Amide I at peak $\left(1669 \mathrm{~cm}^{-1}\right)$ are higher in HC samples compared to the control. The lower levels of glycogen in the HC samples could be linked to lower levels of progesterone due to its role in promoting sub-nuclear glycogen accumulation. The same could be said for the higher levels of proteins detected (Phenylalanine, Tryptophan, and Amide I). There is also a consistent change in the shoulder of Amide I, which is a change in Amide I protein position and folding between HC positive and negative samples. Overall protein synthesis may be increased due to the constant level of hormones present.

The LV scores scatter plot Figure 3.4(B) shows good separation between HC positive samples and HC negative samples. There is a small amount of overlapping which could be due to a number of factors. Multiple types of contraceptive are available which contain different types and levels of hormones, including implants, injectable contraceptive, progesterone pills, oestrogen and progesterone pills, combined oral and the patch all of which work by maintaining a constant level of hormones in the body thus preventing the rise and fall of oestrogen and progesterone. Hence they may work differently and individual patients will also respond differently to the levels of hormones present. The loadings 3.4(C) from LV1 show that glycogen (483 and $1386 \mathrm{~cm}^{-1}$ ) and proteins and lipids (1146, 1450, $1566 \mathrm{~cm}^{-1}$ ) and Amide I $\left(1669 \mathrm{~cm}^{-1}\right)$ are the main discriminating factors between HC positive and HC negative samples 
The PLS-DA prediction plot Figure 3.4(D) shows excellent classification with a sensitivity of $100 \%$ and specificity of $100 \%$.
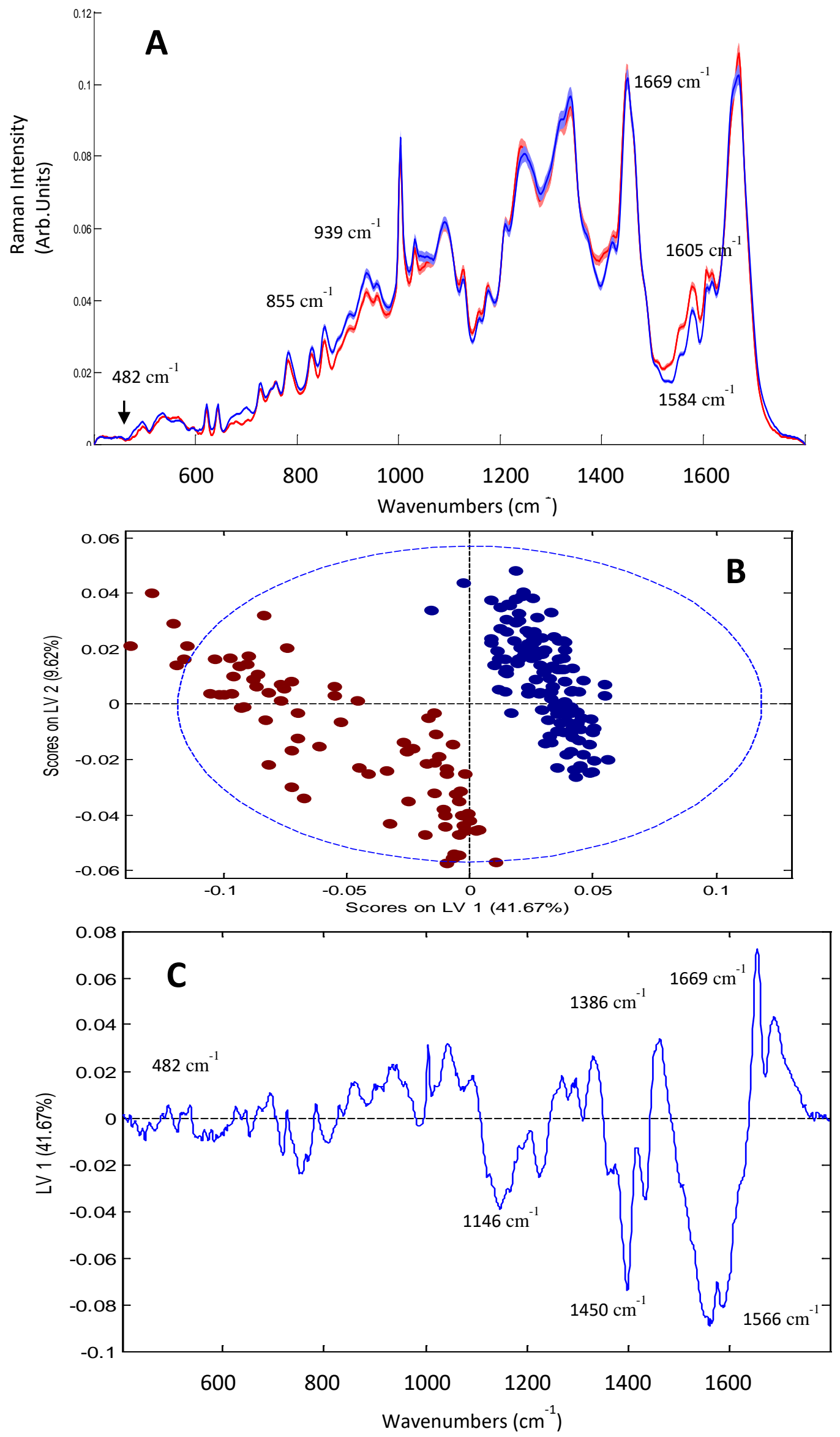


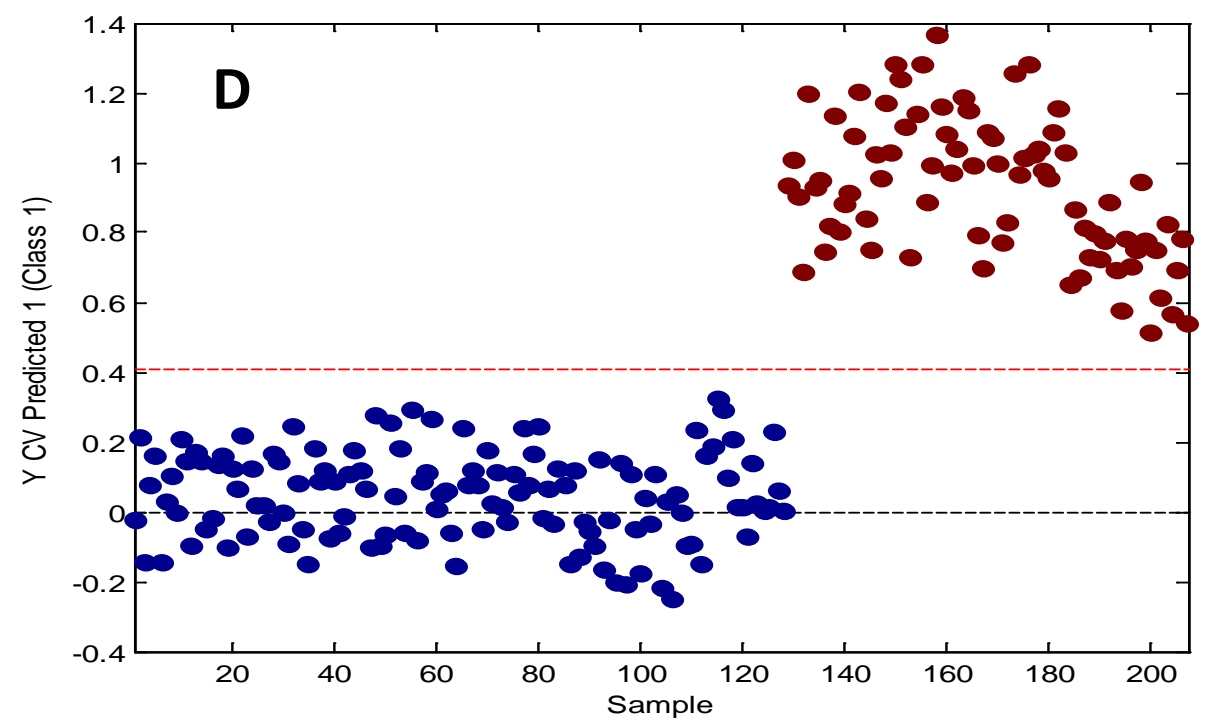

Figure 3.4 (A) Mean Raman spectra from HC positive and HC negative cells. Shading denotes the standard deviation, (B) LV scatter scores plot of HC negative (blue) and HC positive (red), (C) LV1 loadings, (D) PLS-DA prediction plot. 


\subsubsection{Phase of Menstrual Cycle vs High Grade Dyskaryosis}

It is important to determine if the changes observed throughout the menstrual cycle as seen in Figure 3.2(A) would affect the ability of Raman spectroscopy to discriminate HSIL from normal cells affected by the normal maturation of the cervical epithelium controlled by both the rise and fall of progesterone and oestrogen. For this part of the study, spectra from HSIL cells Figure 3.5(A) were recorded from 15 HPV positive, high grade dyskaryotic samples and compared to an equivalent number of spectra from negative samples from days 7-21 of the menstrual cycle, all of which were HPV negative. Figure 3.5(B) shows the mean spectra from negative samples from days 7-21 of the menstrual cycle and spectra recorded from-HSIL cells. The LV scores scatterplot in Figure 3.5(C) shows that HSIL cells separate well from normal cells on the first LV. This shows that regardless of when a sample is taken during day 7-21 of the menstrual cycle, HSIL cells can still be effectively discriminated from cytology negative cells using Raman spectroscopy. Spectral changes due to the hormonal influence of oestrogen and progesterone seem to be less than the spectral changes due to the biochemical changes in the dyskaryotic cells. The loadings from LV1 in Figure 3.5(D) show that glycogen $(495,1080$, 1120, 1380, $1458 \mathrm{~cm}^{-1}$ ), nucleic acids (780 and $1487 \mathrm{~cm}^{-1}$ ), Amide III and Amide I proteins (1239 $\mathrm{cm}^{-1}$ and $1669 \mathrm{~cm}^{-1}$ respectively) and tryptophan and phenylalanine $\left(1605 \mathrm{~cm}^{-1}\right)$ mainly contribute towards the discrimination between normal and HSIL cells. As the HSIL cells are a result of a high risk HPV infection, the biochemical difference in glycogen, proteins and nucleic acids can be attributed to the downstream effects of the HPV infection. The predictions plot Figure 3.5(E) from the PLS-DA model shows excellent classification of the negative samples (all menstrual cycle phases) and the dyskaryotic samples with sensitivitiy of $98 \%$ and a specificity of $97 \%$. 

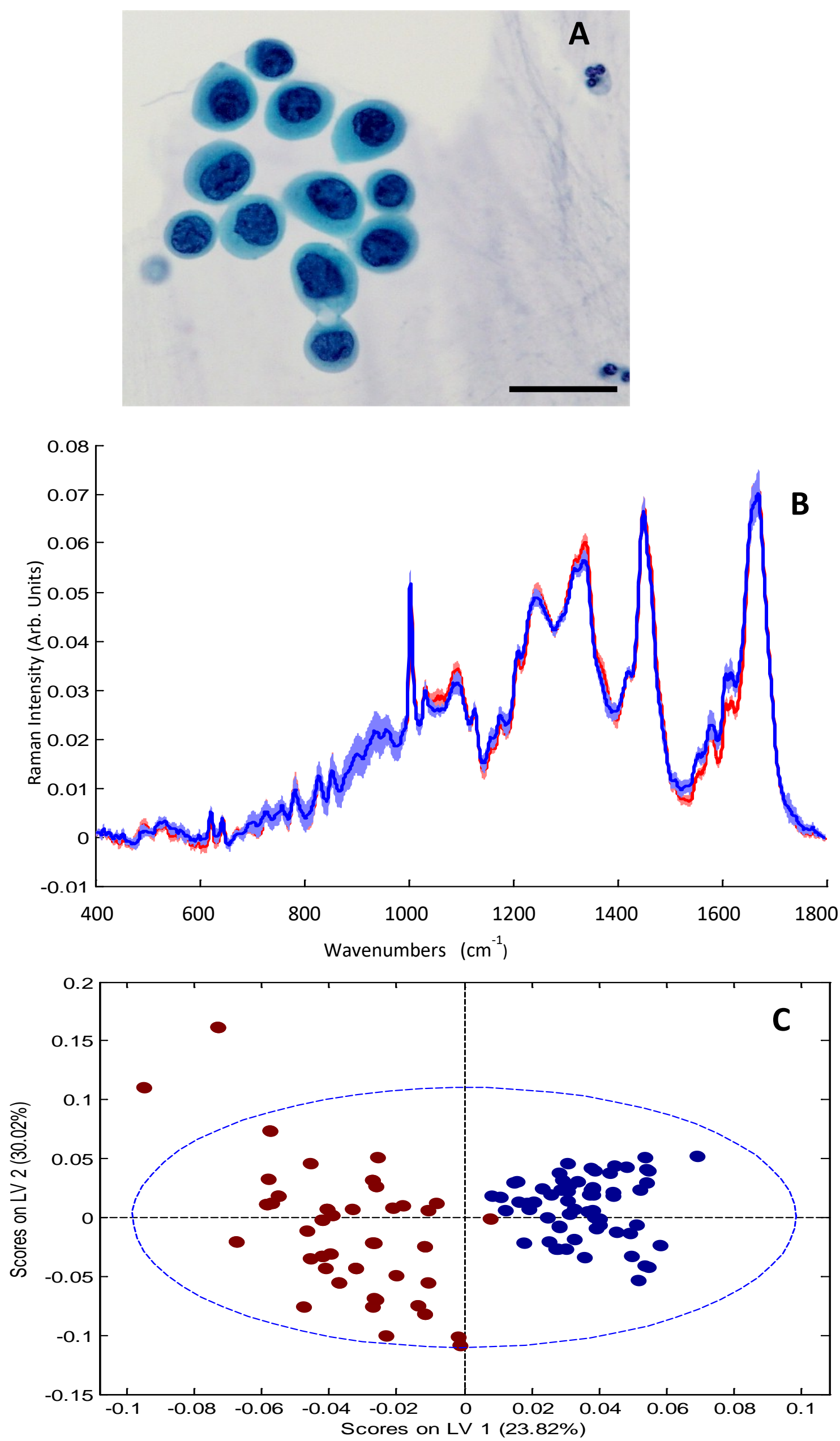

Scores on LV1 (23.82\%) 

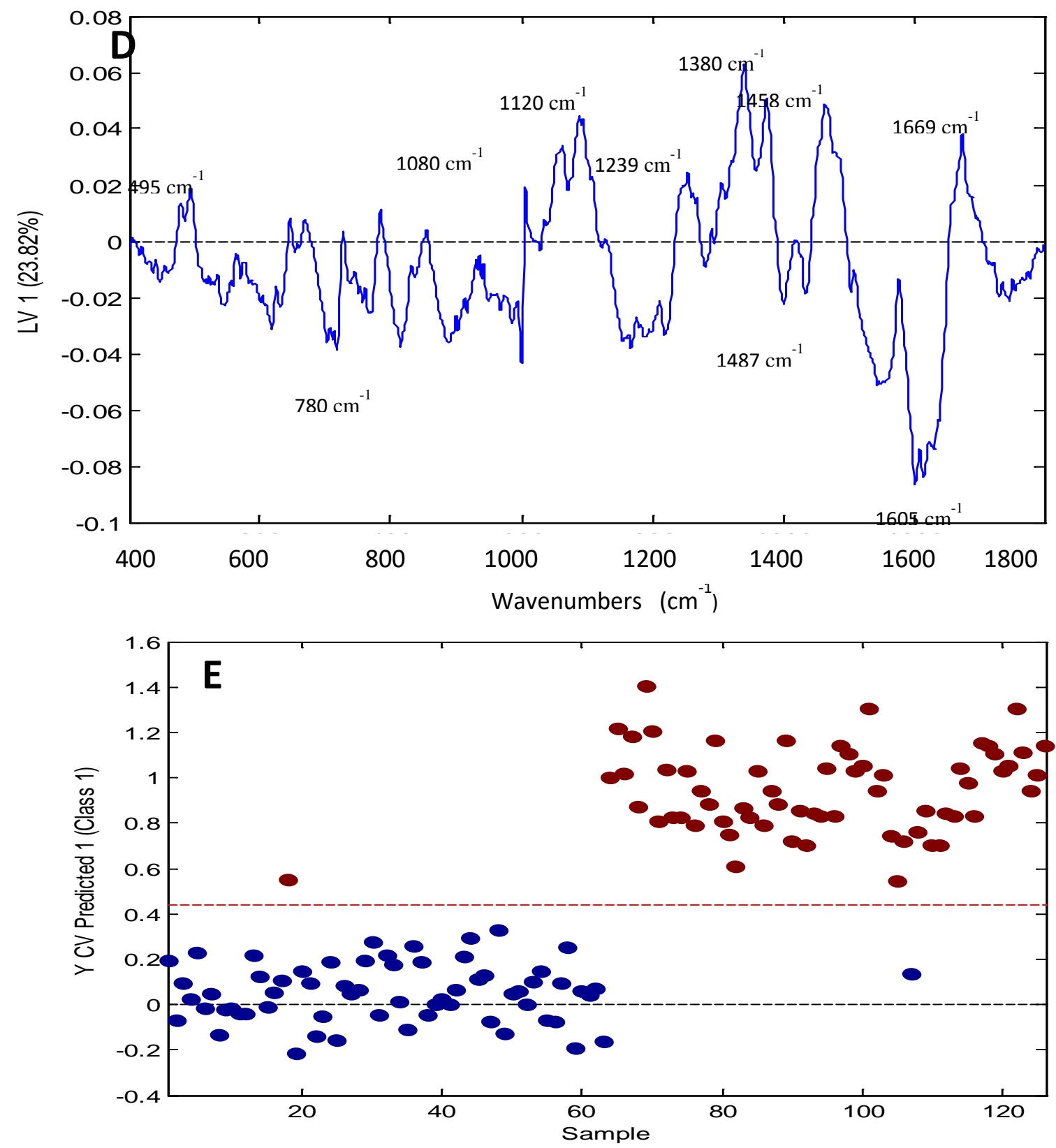

Figure 3.5 (A) Pap stained HSIL cells. Bar $=35 \mu \mathrm{m}$, (B) Mean Raman spectra from negative samples from days 7-21 of the menstrual cycle (red) and spectra from HSIL positive samples (blue). Shading denotes the standard deviation, (C) LV scores scatter plot of HSIL positive samples (red) and negative samples (blue), (D) LV1 loadings, (E) PLS-DA prediction plot. 


\subsubsection{HC positive samples vs High Grade Dyskaryosis}

It is important to determine if the use of HC will also affect the ability of Raman spectroscopy to discriminate normal HC positive cells from HSIL cells. Figure 3.6(A) shows the mean Raman spectra of HC positive negative samples and spectra from HSIL cells. The LV scores scatterplot in Figure 3.6(B) shows that spectra from HC positive samples separate from spectra from HSIL cells from high grade dyskaryotic samples on the first LV component with minimal overlap. Figure 3.6(C) shows the LV1 loadings which indicate that the main differences between the HC positive cells and HSIL cells are very similar to those found for the HC negative and high grade dyskaryotic samples. Glycogen (482, 1261 and $1381 \mathrm{~cm}^{-1}$ ), nucleic acids $\left(781 \mathrm{~cm}^{-1}\right)$, and proteins $\left(1450,1560\right.$ and $\left.1669 \mathrm{~cm}^{-1}\right)$ again contribute towards the discrimination. As before, it appears that the overtaking of the host cell machinery by HPV causes more of a biochemical change within the cell than the biochemical changes associated with the use of HC. The predictions plot from the PLS-DA model shows excellent classification of the negative samples (HC positive) and the HSIL cells from high grade dyskaryotic samples Figure 3.6(D) with sensitivity of 96\% and specificity of 98\%.

(Kanter et al., 2009) showed that hormonal status influences Raman spectra from the cervix in vivo and that incorporating hormonal status into their classification algorithm increased the accuracy from $88 \%$ to $94 \%$. However, the present study and that of (Romeo et al., 2003) on exfoliated cervical cells showed good discrimination between normal and abnormal samples regardless of phase of the menstrual cycle and of whether the woman was taking oral contraceptives or not. 

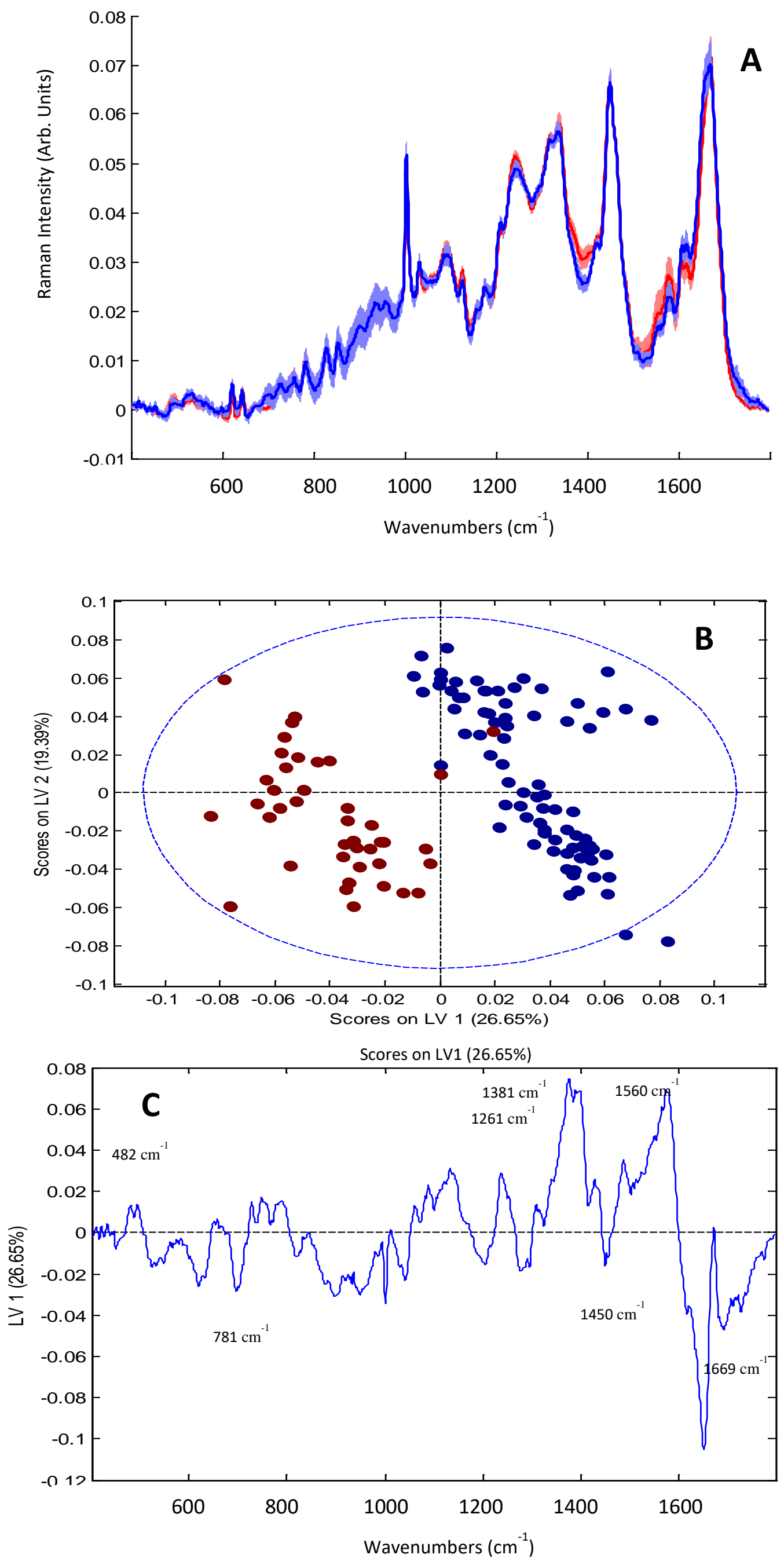


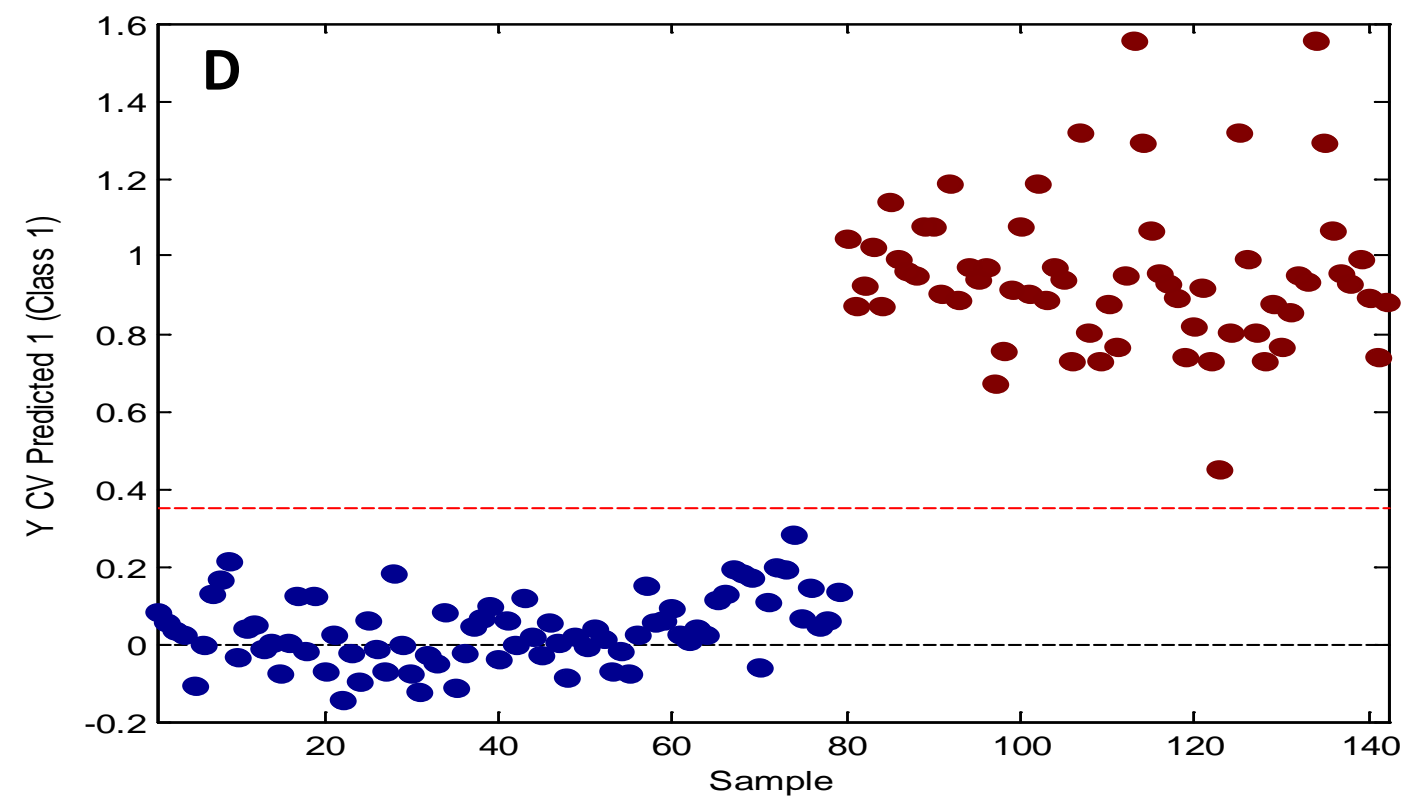

Figure 3.6 (A) Mean Raman spectra from negative HC positive samples (red) and spectra from HSIL cells (blue). Shading denotes the standard deviation, (B) LV scores scatter plot of HSIL samples (red) and negative HC positive samples (blue), (C) LV1 loadings, (D) PLS-DA prediction plot.

\subsection{Conclusion}

This study has shown that the day a Pap smear is taken during days 7-21 of the menstrual cycle will have an effect on the spectra with regard to the level of glycogen and proteins. It should be noted, however, that this study assumes that each patient recruited follows the standard 28 day cycle, and that the patient details recorded for each sample were correct. It is possible for women have a longer or shorter cycle, hence this variation may have influenced our analysis. Postmenopausal samples represent a problem for Raman based screening due to their lack of cellular material and presence of cellular debris and mucus. The use of HC causes the most variability. Further study would be required to determine which hormone is causing the discrimination between $\mathrm{HC}$ positive and $\mathrm{HC}$ negative samples. These findings suggest that the use of oral contraceptives and the day on which the Pap smear was taken during the menstrual cycle should be incorporated into the data analysis to reduce variability between patient samples.

Despite this, however, the variability between days of the menstrual cycle or use of HC did not hinder the ability of Raman spectroscopy to discriminate cytology negative cells from HSIL cells. The biochemical changes induced in HSIL cells due to an active HPV infection 
were more pronounced than the biochemical changes due to the menstrual cycle or the use of hormone based contraceptives. It is acknowledged that the study is limited in focussing only on HSIL positive samples and a further study would be required to include low grade (LSIL) samples. In conclusion, this study highlights the scope of Raman spectroscopy for cervical screening despite the presence of biochemical changes associated with the menstrual cycle and the use of HC.

\section{References}

Adams, A. L. et al. (2006) 'Negative Colposcopic Biopsy After Positive Human Papilloma Virus (HPV) DNA Testing’, American Journal of Clinical Pathology, 125(May), pp. 413418. doi: 10.1309/BPPUL3BK9GLBPNMG.

Arbyn M, Bergeron C, Klinkhamer P, Martin-Hirsch P, Siebers AG, B. J. (2008) 'Liquid compared with conventional cervical cytology: a systematic review and meta-analysis’, Obstet Gynecol, 111(1), pp. 167-77.

Arbyn, M. et al. (2007) 'Burden of cervical cancer in Europe: Estimates for 2004', Annals of Oncology, 18(10), pp. 1708-1715. doi: 10.1093/annonc/mdm079.

Arbyn, M. and Ronco, G. (2009) 'How to evaluate emerging technologies in cervical cancer screening?’, ... Journal of Cancer, 125(11), pp. 2489-2496. doi: 10.1002/ijc.24774.How.

Baker, M. J. et al. (2018) 'Clinical applications of infrared and Raman spectroscopy: state of play and future challenges’, The Analyst. Royal Society of Chemistry, (1985). doi: 10.1039/C7AN01871A.

Baldur-Felskov, B. et al. (2014) 'Early impact of human papillomavirus vaccination on cervical neoplasia - Nationwide follow-up of young danish women', Journal of the National Cancer Institute, 106(3). doi: 10.1093/jnci/djt460.

Ballabio, D Consonni, V. (2013) 'Classification toold in chemistry.Part 1: Linear models. PLS-DA', royal society of chemsitry, 5, pp. 3790-3798.

Ballabio, D. and Consonni, V. (2013) 'Classification tools in chemistry. Part 1: linear models. PLS-DA’, Analytical Methods, 5(16), p. 3790. doi: 10.1039/c3ay40582f.

Basicmedicalkey.com (2016) No Title. Available at: https://basicmedicalkey.com/cervicalbenign-and-non-neoplastic-conditions/.

Behl, I. et al. (2017) 'Development of methodology for Raman microspectroscopic analysis of oral exfoliated cells', Analytical Methods. Royal Society of Chemistry, 9, pp. 1-22. doi: 10.1039/C6AY03360A.

Bellisola, G. and Sorio, C. (2012) 'Infrared spectroscopy and microscopy in cancer research and diagnosis.', American journal of cancer research, 2(1), pp. 1-21. Available at: 
http://www.pubmedcentral.nih.gov/articlerender.fcgi?artid=3236568\&tool=pmcentrez\&rende rtype=abstract.

Bonnier, F. et al. (2014) 'Processing ThinPrep cervical cytological samples for Raman spectroscopic analysis’, Anal. Methods, 6(19), pp. 7831-7841. doi: 10.1039/C4AY01497A.

Boron, W. F. (2005) Medical physiology. 3rd edn. Elsevier Ltd.

Bosch, F. X. et al. (2002) 'The causal relation between human papillomavirus and cervical cancer.', Journal of Clinical Pathology, 55(4), pp. 244-65. doi: 10.1136/jcp.55.4.244.

Brereton, R. G. and Lloyd, G. R. (2014) 'Partial least squares discriminant analysis: Taking the magic away’, Journal of Chemometrics, 28(4), pp. 213-225. doi: 10.1002/cem.2609.

Brozek-Pluska, B. et al. (2012) 'Raman spectroscopy and imaging: applications in human breast cancer diagnosis’, The Analyst, 137(16), p. 3773. doi: 10.1039/c2an16179f.

Bulten, J. et al. (2011) 'European guidelines for quality assurance in cervical histopathology', Acta Oncologica, 50(5), pp. 611-620. doi: 10.3109/0284186X.2011.555779.

Burd, E. (2003) ‘Human papillomavirus and cervical cancer’, Clin Microbiol Rev, 16(1), pp. 1-17. doi: 10.1128/CMR.16.1.1.

CervicalCheck (2013) Organisational and Clinical Guidance for Quality Assured Colposcopy Services.

Chiriboga, L. et al. (1998) 'Infrared spectroscopy of human tissue. I. Differentiation and maturation of epithelial cells in the human cervix', Biospectroscopy, 4(1), pp. 47-53. doi: 10.1002/(SICI)1520-6343(1998)4:1<47::AID-BSPY5>3.0.CO;2-P.

Clinic, C. (2014) ‘Cle’. Available at: http://www.clevelandclinic.org/health/healthinfo/docs/0600/0642.asp?index $=4711$.

Cohenford, M. (1997) 'Infrared spectroscopy of normal and abnormal cervical smears: evaluation by principal component analysis.', Gynecologic oncology, 66(1), pp. 59-65. doi: 10.1006/gyno.1997.4627.

Cuzick, J. et al. (2013) 'Comparing the performance of six human papillomavirus tests in a screening population’, British Journal of Cancer, 108(4), pp. 908-913. doi: 10.1038/bjc.2013.22.

Diem, M. et al. (2002) 'IR spectra and IR spectral maps of individual normal and cancerous cells’, Biopolymers - Biospectroscopy Section, 67(4-5), pp. 349-353. doi: 10.1002/bip.10109.

Diem, M. et al. (2013) 'Molecular pathology via IR and Raman spectral imaging', Journal of Biophotonics, 6(11-12), pp. 855-886. doi: 10.1002/jbio.201300131.

Dillner, J. et al. (2008) 'Long term predictive values of cytology and human papillomavirus testing in cervical cancer screening: joint European cohort study', Bmj, 337(oct13 1), pp. a1754-a1754. doi: 10.1136/bmj.a1754.

Doorbar, J. et al. (2012) 'The biology and life-cycle of human papillomaviruses', Vaccine. 
Elsevier Ltd, 30(SUPPL.5), pp. F55-F70. doi: 10.1016/j.vaccine.2012.06.083.

Downes, A. and Elfick, A. (2010) 'Raman spectroscopy and related techniques in biomedicine’, Sensors, 10(3), pp. 1871-1889. doi: 10.3390/s100301871.

Duraipandian, S. et al. (2013) 'Integrated fingerprint and high wavenumber confocal Raman spectroscopy for in vivo diagnosis of cervical precancer', Analytical Chemistry, 84(14), p. 85720Z. doi: 10.1117/12.2003058.

Ferlay, J. et al. (2015) 'Cancer incidence and mortality worldwide: Sources, methods and major patterns in GLOBOCAN 2012', International Journal of Cancer, 136(5), pp. E359E386. doi: 10.1002/ijc.29210.

Fouad, Y. A. and Aanei, C. (2017) 'Revisiting the hallmarks of cancer', American Journal of Cancer Research, 7(5), pp. 1016-1036. doi: 10.1016/j.jmwh.2009.11.004.

Garland, S. M. et al. (2016) 'Impact and effectiveness of the quadrivalent human papillomavirus vaccine: A systematic review of 10 years of real-world experience', Clinical Infectious Diseases, 63(4), pp. 519-527. doi: 10.1093/cid/ciw354.

Gautam, R. et al. (2015) 'Review of multidimensional data processing approaches for Raman and infrared spectroscopy’, EPJ Techniques and Instrumentation. EPJ Techniques and Instrumentation, 2(1), p. 8. doi: 10.1140/epjti/s40485-015-0018-6.

General cytopathology (2016). Available at:

http://pathology.jhu.edu/cytopath/masterclass/general/1gen16.htm.

Gettyimages (2018). Available at: https://www.gettyimages.ie/detail/illustration/menstrualcycle-illustration-stock-graphic/502865065.

González-Solís, J. L. et al. (2013) 'Cervical cancer detection based on serum sample Raman spectroscopy’, Lasers in Medical Science, 29(3), pp. 979-985. doi: 10.1007/s10103-0131447-6.

González-Solís, J. L. et al. (2014) 'Cervical cancer detection based on serum sample Raman spectroscopy’, Lasers in Medical Science, 29(3), pp. 979-985. doi: 10.1007/s10103-0131447-6.

Gray, N. M. et al. (2006) 'Psychological effects of a low-grade abnormal cervical smear test result: Anxiety and associated factors’, British Journal of Cancer, 94(9), pp. 1253-1262. doi: 10.1038/sj.bjc.6603086.

Haedicke, J. and Iftner, T. (2016) 'A review of the clinical performance of the Aptima HPV assay’, Journal of Clinical Virology, 76, pp. S40-S48. doi: 10.1016/j.jcv.2015.10.027.

HealthDxS (2017) No Title. Available at: https://healthdxs.com/en/thinprep/.

HIQA (2017) 'Health technology assessment of human papillomavirus testing as the primary screening method for prevention of cervical cancer', Health Information and Quality Authority, (May), pp. 1-347.

Santos I.P, E.M. Barroso (2017) 'Raman spectroscopy for cancer detection and cancer surgery guidance: translation to the clinics’, Analyst, 142, pp. 3025-3047. 
Ikenberg, H. et al. (2013) 'Screening for cervical cancer precursors with p16/Ki-67 dualstained cytology: Results of the PALMS study', Journal of the National Cancer Institute, 105(20), pp. 1550-1557. doi: 10.1093/jnci/djt235.

Jess, P. R. T. et al. (2007) 'Early detection of cervical neoplasia by Raman spectroscopy', International Journal of Cancer, 121(12), pp. 2723-2728. doi: 10.1002/ijc.23046.

Kamemoto, L. E. et al. (2010) 'Near-infrared micro-Raman spectroscopy for in vitro detection of cervical cancer’, Appl Spectrosc, 64(3), pp. 255-261. doi: 10.1366/000370210790918364.

Kanter, E. M. et al. (2009) 'Application of Raman spectroscopy for cervical dysplasia diagnosis’, Journal of Biophotonics, 2(1-2), pp. 81-90. doi: 10.1002/jbio.200910001.

Kearney, P., Traynor, D., Bonnier, F., Lyng, F. M., et al. (2017) 'Raman spectral signatures of cervical exfoliated cells from liquid-based cytology samples.', Journal of biomedical optics, 22(10), pp. 1-10. doi: 10.1117/1.JBO.22.10.105008.

Kearney, P., Traynor, D., Bonnier, F., Lyng, F. M., et al. (2017) 'Raman spectral signatures of cervical exfoliated cells from liquid-based cytology samples’, Journal of Biomedical Optics, 22(10), p. 1. doi: 10.1117/1.JBO.22.10.105008.

Kerr, L. T. et al. (2016) 'Methodologies for bladder cancer detection with Raman based urine cytology’, Anal. Methods, 8(25), pp. 4991-5000. doi: 10.1039/C5AY03300D.

Kitchener, H. C. et al. (2011) 'Automation-assisted versus manual reading of cervical cytology (MAVARIC): A randomised controlled trial', The Lancet Oncology. Elsevier Ltd, 12(1), pp. 56-64. doi: 10.1016/S1470-2045(10)70264-3.

Kitchener, H. C. et al. (2011) 'MAVARIC - A comparison of automation-assisted and manual cervical screening: A randomised controlled trial', Health Technology Assessment, 15(3), pp. 1-176. doi: 10.3310/hta15030.

Kohavi, R. (1995) 'A Study of Cross-Validation and Bootstrap for Accuracy Estimation and Model Selection 2 Methods for Accuracy Estimation', Proc. of IJCAI'95, (March 2001), pp. 1137-1145. doi: 10.1067/mod.2000.109031.

Kong, K. et al. (2015) 'Raman spectroscopy for medical diagnostics - From in-vitro biofluid assays to in-vivo cancer detection', Advanced Drug Delivery Reviews. The Authors, 89, pp. 121-134. doi: 10.1016/j.addr.2015.03.009.

Koss, L. G. (2005) Diagnostic Cytology and Its Histopathologic Bases. 5th edn, Volume 5. 5th edn. Edited by L. G.Koss. Lippincott Williams \& Wilkins.

Krishna, C. M. et al. (2006) 'Vibrational Spectroscopy Studies of Formalin-Fixed Cervix Tissues Vibrational Spectroscopy Studies of Formalin-Fixed Cervix Tissues’, Biopolymers, 85(3), pp. 214-221. doi: 10.1002/bip.

Laboratory,T.P.K. Spectroscopic Characterization (2012). Available at: https://www3.nd.edu/kamatlab/facilities_spectroscopy.html. 
Lyng, F. M. et al. (2015) 'Raman spectroscopy for screening and diagnosis of cervical cancer’, Analytical and Bioanalytical Chemistry, 407(27), pp. 8279-8289. doi:

10.1007/s00216-015-8946-1.

Lyng, F. M. et al. (2016) 'Raman spectroscopy for screening and diagnosis of cervical cancer’. doi: 10.1007/s00216-015-8946-1.

Mahadevan-jansen, A. (2010) ‘Disease Detection’, Arn J Obstet Gynecol., 200(5), pp. 1-13. doi: 10.1016/j.ajog.2008.11.024.Effect.

Mahadevan-Jansen, Follen. M ,Nirmala Ramanujam.M, Utzinger.M,Richards-Kortum (1998) 'Development of a Fiber Optic Probe to Measure NIR Raman Spectra of Cervical Tissue In Vivo', Photochem Photobiol, 68, pp. 427-31. doi: https://doi.org/10.1111/j.17511097.1998.tb09703.x.

McGrath, C. J. (2017) 'Role of p16 testing in cervical cancer screening among HIV-infected women’, PLoS ONE, 12(10), pp. 1-9. doi: 10.1371/journal.pone.0185597.

Meade, A. (2010) 'Studies of Chemical fixation effects in Human cell lines using Raman Mircrospectroscopy’, Bioanalytical chemistry, 369(5), pp. 1781-1791. doi: 10.1007/s00216009-3411-7.

Medipally, D. K. R. et al. (2017) 'Development of a high throughput (HT) Raman spectroscopy method for rapid screening of liquid blood plasma from prostate cancer patients', The Analyst. Royal Society of Chemistry, 142(8), pp. 1216-1226. doi: 10.1039/C6AN02100J.

Medlineplus (2018). Available at: https://medlineplus.gov/ency/imagepages/19263.htm.

Mo, J. (2009) 'High wavenumber Raman spectroscopy for in vivo detection of cervical dysplasia’, Anal. Chem, 81(21), pp. 8908-8915. doi: 10.1021/ac9015159.

Movasaghi, Z., Rehman, S. and U., R. I. (2007) 'Raman spectroscopy of biological tissues.', Applied Spectroscopy Reviews, 42, pp. 493-541.

Munoz, N. et al. (2010) 'Impact of Human Papillomavirus (HPV)-6/11/16/18 Vaccine on All HPV-Associated Genital Diseases in Young Women', Journal of the National Cancer Institute, 102(5), pp. 325-339. doi: 10.1093/jnci/djp534.

Nair.A, H. T. (2010a) A Case Based, Clinical Guide. Edited by S. Science+ and B. (Genevieve N.-P. Media. New York: Contemporary Endocrinology.

Nair.A, H. T. (2010b) A case based,clinical guide. Edited by Genevieve NeaL-perry.

Nanda K, McCrory DC, Myers ER, Bastian LA, Hasselblad V, Hickey JD, et al. (2000) 'Accuracy of the Papanicolaou Test in Screening for and Follow-up of Cervical Cytologic Abnormalities', Ann Intern Med, 132, pp. 810-819. doi: 10.7326/0003-4819-132-10200005160-00009.

Shambayati.B (2011) Cytopathology. First edit. Oxford University Press. 
O’ Sullivan, B. (2015) Manual of clinical oncology. 9th edn. Edited by Wiley Blackwell.

oncohemakey.com (2016). Available at: https://oncohemakey.com/pathology-5/.

Ostrowska, K. M. et al. (2010) 'Investigation of the influence of high-risk human papillomavirus on the biochemical composition of cervical cancer cells using vibrational spectroscopy', The Analyst, 135(12), p. 3087. doi: 10.1039/c0an00571a.

Wong P.T.T, M.K. Senterman, P. Jackli, R.K. Wong, S. Salib, C.E. Campbell, R. Feigel, , W. Faught, M. F. K. F. (2002) Biopolymers.

Pereira dos Santos, I. et al. (2017) 'Raman Spectroscopy for cancer diagnostics and cancer surgery guidance: translation to the clinics’, The Analyst, pp. 3025-3047. doi:

10.1039/C7AN00957G.

Petros PINIDISa; Panagiotis TSIKOURASa; Georgios IATRAKISb,c; Stefanos

ZERVOUDISb,c; Zacharoula KOUKOULIa; Anastasia BOTHOUb, c; G. Galazios. S. V. (2016) 'Human Papilloma Virus’ Life Cycle and Carcinogenesis', Maedica, 11(1), pp. 48-54.

Petry, K. U. et al. (2017) 'A model to evaluate the costs and clinical effectiveness of human papilloma virus screening compared with annual papanicolaou cytology in Germany’, European Journal of Obstetrics Gynecology and Reproductive Biology. Elsevier Ireland Ltd, 212, pp. 132-139. doi: 10.1016/j.ejogrb.2017.03.029.

Pirro, V. et al. (2017) 'Intraoperative assessment of tumor margins during glioma resection by desorption electrospray ionization-mass spectrometry', Proceedings of the National Academy of Sciences, 114(26), p. 201706459. doi: 10.1073/pnas.1706459114.

Poljak, M. et al. (2016) 'Commercially available molecular tests for human papillomaviruses (HPV): 2015 update’, Journal of Clinical Virology, 76, pp. S3-S13. doi: 10.1016/j.jcv.2015.10.023.

Powers, A., Farhat, S. and Shiboski, S. (2011) 'NIH Public Access', 116(6), pp. 1373-1380. doi: 10.1097/AOG.0b013e3181fe777f.Rate.

RAMAN, C. V. and KRISHNAN, K. S. (1928) ‘A New Type of Secondary Radiation', Nature, 121(3048), pp. 501-502. doi: 10.1038/121501c0.

Ramos, I. R. et al. (2016) 'Raman spectroscopy for cytopathology of exfoliated cervical cells’, in Faraday Discuss., pp. 187-198. doi: 10.1039/C5FD00197H.

Ramos, I. R. M., Malkin, A. and Lyng, F. M. (2015) 'Current Advances in the Application of Raman Spectroscopy for Molecular Diagnosis of Cervical Cancer', BioMed Research International, 2015, pp. 1-9. doi: 10.1155/2015/561242.

Rashid, N. et al. (2014) 'Raman microspectroscopy for the early detection of pre-malignant changes in cervical tissue', Experimental and Molecular Pathology. Elsevier Inc., 97(3), pp. 554-564. doi: 10.1016/j.yexmp.2014.10.013.

Robichaux-Viehoever.A, Elizabeth Kanter E, Heidi Shappell.H, Billheimer D, Jones H, III, and A. M.-J. (2007) 'Characterization of Raman Spectra Measured in Vivo for the Detection of Cervical Dysplasia’, Applied Spectroscopy, Vol 61(9), pp. 986-993. doi:

https://doi.org/10.1366/000370207781746053. 
Rodriguez, E. F. et al. (2012) 'Atypical squamous cells of undetermined significance in patients with HPV positive DNA testing and correlation with disease progression by age group: An institutional experience', International Journal of Clinical and Experimental Pathology, 5(5), pp. 428-435.

Romeo, M. et al. (1998) 'Infrared microspectroscopy and artificial neural networks in the diagnosis of cervical cancer.', Cellular \& Molecular Biology, 44(1), pp. 179-187.

Romeo, M. J. et al. (2003) 'Removal of blood components from cervical smears: implications for cancer diagnosis using FTIR spectroscopy.', Biopolymers, 72(1), pp. 69-76. doi: 10.1002/bip.10284.

Ronco, G. et al. (2010) 'Efficacy of human papillomavirus testing for the detection of invasive cervical cancers and cervical intraepithelial neoplasia: a randomised controlled trial', The Lancet Oncology, 11(3), pp. 249-257. doi: 10.1016/S1470-2045(09)70360-2.

Ronco, G. et al. (2014) 'Efficacy of HPV-based screening for prevention of invasive cervical cancer: Follow-up of four European randomised controlled trials', The Lancet, 383(9916), pp. 524-532. doi: 10.1016/S0140-6736(13)62218-7.

Rozemeijer, K. et al. (2016) 'Comparing SurePath, ThinPrep, and conventional cytology as primary test method: SurePath is associated with increased CIN II+detection rates', Cancer Causes and Control. Springer International Publishing, 27(1), pp. 15-25. doi: 10.1007/s10552-015-0678-1.

RUBINA, S., VIDYASAGAR, M. S. and MURALI KRISHNA, C. (2013) 'Raman Spectroscopic Study on Prediction of Treatment Response in Cervical Cancers', Journal of Innovative Optical Health Sciences, 06(02), p. 1350014. doi: 10.1142/S1793545813500144.

Rubina1,S, C, Murali, K. (2015) 'Raman spectroscopy in cervical cancers: An update', Journal of cancer research and therapeutics, 11(1), pp. 10-17.

Sahdev, A. (2010) 'Cervical Tumors', Seminars in Ultrasound, CT and MRI. Elsevier Inc., 31(5), pp. 399-413. doi: 10.1053/j.sult.2010.07.004.

Sanjosé, S. et al. (2007) 'Worldwide prevalence and genotype distribution of cervical HPV in women with normal cytology', Lancet Infect, 7(7), pp. 453-459. doi: 10.1016/S14733099(07)70158-5.

Sankaranarayanan R, S. J. (2003) Colposcopy and Treatment of Cervical Intraepithelial Neoplasia., World Health Organization - International Agency for Research on Cancer (IARC). Available at: http://screening.iarc.fr/colpochap.php?lang=1\&chap=12.php.

Schiffman, M., Clifford, G. and Buonaguro, F. M. (2009) 'Classification of weakly carcinogenic human papillomavirus types: Addressing the limits of epidemiology at the borderline', Infectious Agents and Cancer, 4(1), p. 8. doi: 10.1186/1750-9378-4-8.

scienceFacts (2018). Available at: https://www.sciencefacts.net/raman-spectroscopy.html.

Serafin-Higuera, I. et al. (2016) 'Differential proteins among normal cervix cells and cervical cancer cells with HPV-16 infection, through mass spectrometry-based Proteomics (2D-

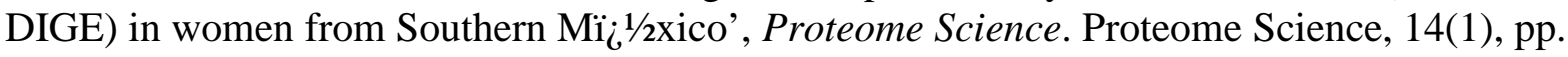


1-9. doi: 10.1186/s12953-016-0099-4.

Shambayati, B. (2011) Cytopathology. 1st edn. Oxford University Press.

Shekinah Medical Centre (2017). Available at:

https://shekinahmedical.com/f5/fliers/flierbase.php?title=Colposcopy\&graphic=colposcope.jp g\&text=colposcopy.

Silverthorn, D. U. (2013) Human Physiology: An integrated Approach. 6th edn. Edited by I. Glenview. Pearson Education.

TabletsManual (2012). Available at: http://www.tabletsmanual.com/wiki/read/colposcopy.

Torre, L. A. et al. (2015) 'Global Cancer Statistics, 2012', CA: a cancer journal of clinicians., 65(2), pp. 87-108. doi: 10.3322/caac.21262.

Troiano, N. W., Ciovacco, W. A. and Kacena, M. A. (2009) 'The Effects of Fixation and Dehydration on the Histological Quality of Undecalcified Murine Bone Specimens Embedded in Methylmethacrylate', Journal of Histotechnology, 32(1), pp. 27-31. doi: 10.1179/his.2009.32.1.27.

Tuschel, D. (2014) Practical Group Theory and Raman Spectroscopy , Part II : Application of Polarization, Spectroscopy. doi: 10.1063/1.1515732.

Urs Utzinger, Douglas L. Heintzelman, Anita Mahadevan-Jansen, Anais Malpica, Michele Follen, and R. R.-K. (2001) 'Near-Infrared Raman Spectroscopy for in Vivo Detection of Cervical Precancers’, Appl. Spectrosc., 55(8), pp. 955-959.

Utzinger, U. et al. (2001) 'Near-Infrared Raman Spectroscopy for in Vivo Detection of Cervical Precancers’, Applied spectroscopy, 55(8), pp. 955-959. doi: 10.1366/0003702011953018.

Vargis, E., Kanter, E. M., et al. (2011) 'Effect of normal variations on disease classification of Raman spectra from cervical tissue’, The Analyst, 136(14), p. 2981. doi: 10.1039/c0an01020k.

Vargis, E., Byrd, T., et al. (2011) 'Sensitivity of Raman spectroscopy to normal patient variability’, Journal of Biomedical Optics, 16(11), p. 117004. doi: 10.1117/1.3646210.

Vargis, E. et al. (2012) 'Near-infrared Raman Microspectroscopy Detects High-risk Human Papillomaviruses’, Translational Oncology, 5(3), pp. 172-179. doi: 10.1593/tlo.12106.

De Vincenzo, R. et al. (2014) 'Long-term efficacy and safety of human papillomavirus vaccination’, International Journal of Women's Health, 6, pp. 999-1010. doi: 10.2147/IJWH.S50365.

Walboomers, J. M. M. et al. (1999) 'Human papillomavirus is a necessary cause of invasive cervical cancer worldwide’, Journal of Pathology, 189(1), pp. 12-19. doi: 10.1002/(SICI)1096-9896(199909)189:1<12::AID-PATH431>3.0.CO;2-F.

Winer, R. L. et al. (2003) 'Genital human papillomavirus infection, incidence and risk factors in a cohort of female university students', American Journal of Epidemiology, 157, pp. 218226. 
Wong, A. A. et al. (2012) 'Comparison of the hybrid capture 2 and cobas 4800 tests for detection of high-risk human papillomavirus in specimens collected in PreserVcyt medium', Journal of Clinical Microbiology, 50(1), pp. 25-29. doi: 10.1128/JCM.05400-11.

Wong, P. T. et al. (1991) 'Infrared spectroscopy of exfoliated human cervical cells: evidence of extensive structural changes during carcinogenesis.', Proceedings of the National Academy of Sciences of the United States of America, 88(24), pp. 10988-10992. doi: 10.1073/pnas.88.24.10988.

Wood, B. R. et al. (1998) 'FTIR Microspectroscopic Study Of Cell Types And Potential Confounding Variables In Screening For Cervical Malignancies’, Biospectroscopy, 4(2), pp. 75-91. doi: 10.1002/(SICI)1520-6343(1998)4:2\&lt;75::AID-BSPY1\&gt;3.0.CO;2-R.

Wu, T. J. et al. (2016) 'Performance of p16 ${ }^{\text {INK4a }}$ ELISA as a primary cervical cancer screening test among a large cohort of HIV-infected women in western Kenya: a 2-year cross-sectional study', BMJ Open, 6(9), p. e012547. doi: 10.1136/bmjopen-2016-012547.

Youssef, M. A. et al. (2016) 'Prevalence of human papilloma virus (HPV) and its genotypes in cervical specimens of Egyptian women by linear array HPV genotyping test', Infectious Agents and Cancer. Infectious Agents and Cancer, 11(1), pp. 1-10. doi: 10.1186/s13027-0160053-1.

Zekan, J., Sirotkovic-skerlev, M. and Skerlev, M. (2011) 'Oncogenic Aspects of HPV Infections of the Female Genital Tract', in InTech (ed.) DNA Replication-Current Advances. Dr Herve S, p. 694. doi: DOI: 10.5772/19165.

Zheng, Z.-M. and Baker, C. C. (2006) 'Papillomavirus genome structure, expression, and post-transcriptional regulation.', Frontiers in bioscience : a journal and virtual library, 11, pp. 2286-302. doi: 1971 [pii].

Zuchna, C. et al. (2010) 'Diagnostic accuracy of guided cervical biopsies: A prospective multicenter study comparing the histopathology of simultaneous biopsy and cone specimen', American Journal of Obstetrics and Gynecology. Elsevier Inc., 203(4), p. 321.e1-321.e6. doi: 10.1016/j.ajog.2010.05.033. 